\title{
Effects of Dilute Acid Activation and Tannin Modification on the Binding Mechanism of Formaldehyde-free Particleboards
}

\begin{abstract}
Feng Chen, ${ }^{\mathrm{a}}$ Baichuan Wang, ${ }^{\mathrm{b}}$ and Xinghua Xia ${ }^{\mathrm{a}, *}$
The development of a formaldehyde-free wood-based panel is a major research direction in the wood-based material industry. Previous research has demonstrated that nitric acid activated fibers and coupling agents could be utilized to manufacture formaldehyde-free medium-density fiberboards. Herein, based on the chemical characteristics of wood, nitric acid and tannin were applied in formaldehyde-free particleboard, featuring suitable mechanical properties and water absorption resistance. The results of modulus of rupture (MOR), surface bonding strength, internal bonding strength, and $2 \mathrm{~h}$ moisture thickness swelling (TS) of formaldehyde-free particleboard (that was synthesized at optimal conditions and satisfied the China National Standards GB/T 4897 (2015) and GB/T 17657 (2013)) are discussed. The investigation of the technological conditions on bond performance showed that when the particleboard was bonded with the conditions of 20/80 nitric acid/particles mass proportion, $50 \%$ tannin concentration, and $135{ }^{\circ} \mathrm{C}$ temperature, the MOR, surface bonding strength, inner bonding strength, and $2 \mathrm{~h}$ TS were better than that of the particles with urea formaldehyde resin adhesive. The synthesis mechanism was studied by both Fourier transform infrared spectroscopy and wide-angle X-ray diffraction, and the chemical composition indicated polycondensation of furfural and tannin, and hydrogen bonding of hydroxyl groups as the reaction mechanism between nitric activation and the tannin coupling agent.
\end{abstract}

Keywords: Formaldehyde-free particleboard; Dilute nitric acid; Tannin; Activation; Wood-based material

Contact information: a: School of Art and Design, Taizhou University, Taizhou 318000, China;

b: School of Wood Engineering, Liaoning Forestry Vocational-Technical College, Shenyang 110101, China;

*Corresponding author: 176945619@qq.com (X.X)

\section{INTRODUCTION}

Wood-based materials with good performance are widely used in the construction industry. In some countries, the proportion of wood-based materials used in construction is as high as $60 \%$, of which the proportion of wall materials is relatively high. The most widely utilized wood-based materials are particleboard, plywood, and fiberboard (Han et al. 2017; Zhao et al. 2019). However, the free formaldehyde and volatile organic compounds (VOCs) released from urea-formaldehyde (UF) resin adhesive in wood-based materials are the greatest sources of pollution, which may endanger human health (Sun and Zhao 2019). When formaldehyde-free adhesives are utilized in the hot-pressing process, the free formaldehyde released from the wood-based panel can be effectively eliminated. There is a technology for gluing wood materials and producing wood-based panels without adhesives, which do not rely on expensive petroleum products as adhesives (Piscitelli et al. 2012; Sun et al. 2019). Generally, this method uses chemical agents for the activation 
treatment of wood surface to significantly increase the amount of hydroxyl groups, which form hydrogen bonds in the hot-pressing process. According to the role of chemical agents, the production method of formaldehyde-free wood-based panels can be divided into the following: oxidation binding method, free radical initiation, acid catalyzed polycondensation, or alkali solution activation method (Ma et al. 2018).

Previous research has demonstrated that nitric acid could be utilized as an oxidizer of formaldehyde-free medium-density fiberboard (MDF) (Zhang et al. 2015). In these studies, the nitric acid solution was sprayed on wood fibers. After or without prior drying treatment, the sprayed fibers were hot-pressed at 180 to $200{ }^{\circ} \mathrm{C}$ to fabricate MDF. The mechanical properties and water resistance of the resulting MDF satisfied the China National Standard GB/T 11718 (2009), and the reaction mechanism was the formation of hydrogen bonding between wood fibers. Furthermore, a coupling agent, such as furfuryl alcohol or maleic anhydride, was added to the activated wood fibers to promote bond performance (Pizzi 2006; Wang et al. 2010). However, although the previous nitric acidcoupling agent could be used for the manufacture of MDF, it has been rarely applied to particleboard production as it causes poor bonding properties and high-water absorption thickness expansion of the particleboard. To overcome this limitation of the application of the nitric acid-coupling agent system, this study explored a method to gain a formaldehydefree particleboard with good bond performance that satisfies the utilization requirements of particleboard.

Tannin is a natural polyphenol compound, which is produced from plant bark or fruit, and its chemistry has attracted considerable interest (Zhao et al. 2018). It is used as an organic raw material in the food, medicine, leather, printing, and dyeing industries because it is cheap, non-toxic, stable, and chemically reactive (Sun and Zhao 2018). Based on the research of tannin chemistry, tannins contain many phenolic hydroxyl groups and can form hydrogen bonds with amide bonds, hydroxyl groups, amino groups, and carboxyl groups (Hameed et al. 2016). Therefore, considering the chemical properties of tannin and the reactivity of nitric acid, there is a possibility to form more hydrogen bonds with wood particles to obtain high strength formaldehyde-free particleboards. In this study, the effects of the nitric acid activation and tannin on bonding performance, and the curing behavior of formaldehyde-free particleboard were investigated.

\section{EXPERIMENTAL}

\section{Materials}

Wattle tannin was purchased from Sengong Rubber Products Co. (Inner Mongolia, China). Nitric acid (NA, guaranteed reagent) was purchased from Shenyang Xinfusite Chemical Co., Ltd. (Shenyang, China). The Korean pine wood particles were screened by a sieving machine to collect particles in the size range of 1.3 to $4.6 \mathrm{~mm}$. Before particleboard manufacturing, the particles (original moisture content $6.2 \mathrm{wt} \%$ ) were dried in impulse-cyclone airflow dryer (MQG-50, Jianda Drying Equipment Co.,Ltd, Changzhou, China) at $180{ }^{\circ} \mathrm{C}$ to a final moisture content of $2 \mathrm{wt} \%$.

The material process is shown in Fig. 1. Nitric acid (initial concentration 68 wt $\%$ ) and distilled water were mixed in a beaker and diluted to a concentration of $32 \mathrm{wt} \%$. In this study, dilute nitric acid was sprayed evenly on the surface of $3 \mathrm{~kg}$ particles with mechanical stirring of $160 \mathrm{rpm} / \mathrm{min}$. The particles mixed with nitric acid were activated for $1 \mathrm{~h}$ at $23{ }^{\circ} \mathrm{C}$. Subsequently, the distilled water was added to the tannin to obtain a tannin solution. An 
amount of $200 \mathrm{~g}$ of tannin solution was added to the activated particles undergoing mechanical stirring. Detailed information on the process conditions is shown in Table 1.

Table 1. Detailed Information of the Process Conditions

\begin{tabular}{|c|c|c|c|}
\hline Groups & Mass Proportion (NA/Particles) & Tannin Concentration (\%) & Temperature $\left({ }^{\circ} \mathrm{C}\right)$ \\
\hline \multirow{4}{*}{ Group A } & $0 / 100$ & & \\
& $5 / 95$ & 50 & 135 \\
& $10 / 90$ & & \\
& $15 / 85$ & 0 & \\
& $20 / 80$ & 10 & 135 \\
Group B & & 20 & \\
& $15 / 85$ & 30 & \\
& & 40 & 105 \\
& & 50 & 115 \\
Group C & & & 135 \\
& $15 / 85$ & 50 & 145 \\
\hline
\end{tabular}
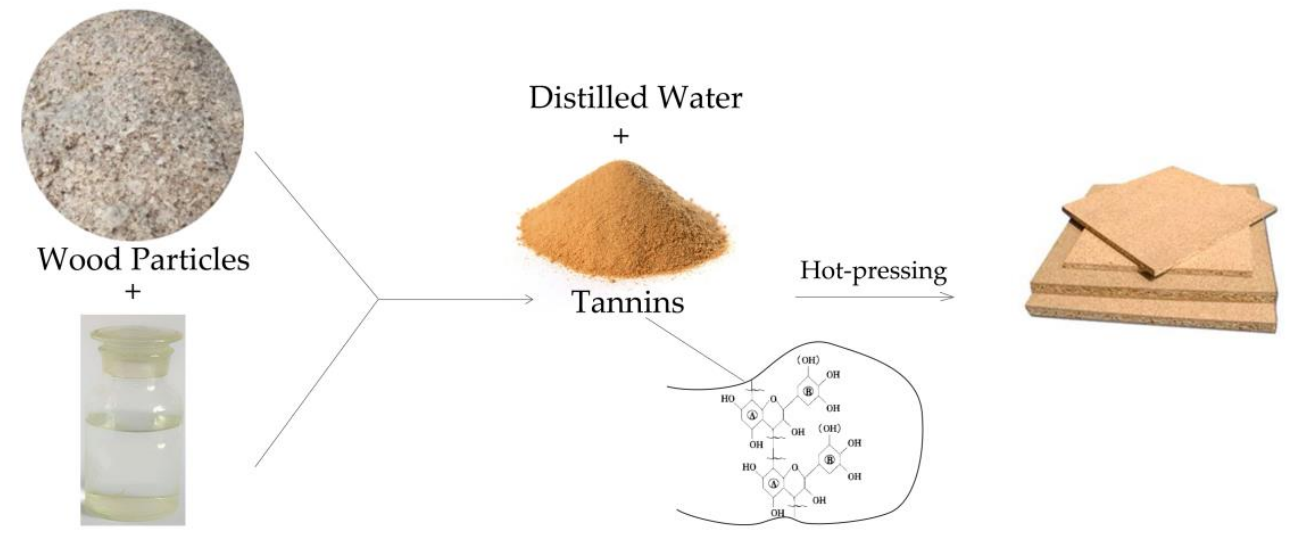

Nitric Acid (HNO3)

Fig. 1. The process of formaldehyde-free particleboard

\section{Methods}

Mechanical properties

The prepared particleboard samples were cut into specimens for tests of mechanical properties according to China National Standard GB/T 4897 (2015) (Song et al. 2018; Zheng et al. 2019). Test specimens for the modulus of rupture (MOR) test had dimensions of $50 \mathrm{~mm} \times 250 \mathrm{~mm}$, whereas the remaining test items (internal bonding strength test and surface bonding strength) had specifications of $50 \mathrm{~mm} \times 50 \mathrm{~mm}$. Then, the specimens (50 $\mathrm{mm} \times 50 \mathrm{~mm}$ ) were cut from each manufactured particleboard and submerged in water with a $\mathrm{pH}$ of 7 for $2 \mathrm{~h}$ and the water absorption thickness swelling ( $2 \mathrm{~h}$ thickness swelling (TS)) was measured according to GB/T 17657 (2013) (Li et al. 2016). Each particleboard was tested in six replications using an RGT-20A electronic mechanics testing machine (Shenzhen REGER Instruments Co., Ltd., Shenzhen, China), and the average values and 
standard deviations were calculated. The statistical significance (SPSS, IBM Corp., v.18.0, Armonk, NY, USA) was considered for p-values $<0.05$.

\section{Determination of $\mathrm{pH}$, holocellulose content, pentosan, and furfural}

Three grams of activated particles were weighed using an analytical electronic balance (range: 0 to $210 \mathrm{~g}$, precision $0.1 \mathrm{mg}$ ) (model AE100; Mettler Instrument, Highstown, NJ, USA) and placed in a beaker. Then, $30 \mathrm{~mL}$ of distilled water was added and brought to a boil for $2 \mathrm{~min}$, then cooled to room temperature. The mixture was then thoroughly stirred. The $\mathrm{pH}$ value of the particles was tested based on the GB/T 6043 (2009) standard (Chen et al. 2017a).

The sodium chlorite method was adopted to determine the cellulose content in wood particles treated with nitric acid solution, with reference to GB/T 2677.10 (1995). The particles were ground into powders using a grinder. Then, the wood powders were deextracted with a mixture of toluene and ethanol, and delignified by sodium chlorite and glacial acetic acid. After washing, the wood powders were baked at $105{ }^{\circ} \mathrm{C}$ and dried to constant weight in a dryer. The mass was measured from a drying oven once every $2 \mathrm{~h}$. When the mass change was less than $0.002 \mathrm{~g}$, the absolute drying status of the substances was determined. The holocellulose content was calculated based on the oven-dried weight (Gao et al. 2017).

Under acid conditions, hemicellulose can decompose pentose. The content of pentose determined by bromination has practical importance for the expression of activated hemicellulose. According to the standard for determination of pentose (GB/T 2677.9 (1994), the sample was weighed and put into a 500-mL round bottom flask, then $10 \mathrm{~g}$ of sodium chloride and $100 \mathrm{~mL}$ of hydrochloric acid with a concentration of $12 \%$ were added. When $30 \mathrm{~mL}$ of solution was distilled out, $30 \mathrm{~mL}$ of hydrochloric acid of the separating funnel was added into the flask to supplement. An amount of $25.0 \mathrm{~mL}$ of sodium bromatesodium bromide solution was sucked into the distillate of a conical flask and was placed under normal temperature closed conditions for $1 \mathrm{~h}$. Then, $10 \%$ potassium iodide solution was added to $10 \mathrm{~mL}$ of solution and sealed for $5 \mathrm{~min}$, and the separated iodine was titrated with sodium thiosulfate standard solution. The furfural content (\%) was calculated according to Eq. 1, and the pentose content (\%) was calculated according to Eq. 2 (Li et al. 2013),

$$
\begin{aligned}
& \text { Furfural content }(\%)=\left(V_{1}-V_{2}\right) \times \mathrm{N} \times 0.024 \times 500 \times 100 \times 100 /[200 \times \mathrm{G} \times(100-\mathrm{W})] \\
& \text { Pentose content }(\%)=\text { Furfural content }(\%) \times 1.376
\end{aligned}
$$

where $V_{1}$ is the amount (mL) of sodium thiosulfate solution consumed in the blank test and $V_{2}$ is the amount (mL) of sodium thiosulfate solution consumed in the sample test, $N$ is the concentration (\%) of sodium thiosulfate standard solution, $G$ is the sample weight (g), and $W$ is the sample moisture content (\%).

\section{Fourier transform infrared spectroscopy (FTIR) characterization}

Using the $\mathrm{KBr}$ disc technique (1 mg of sample powder/300 mg of KBr), the Fourier transform infrared spectrometry measurement was performed with a Nicolet Nexus 6700 FTIR spectrometer (American Thermo Fisher Scientific, Waltham, MA, USA) at a resolution of $4 \mathrm{~cm}^{-1}, 32$ scans, and a scanning range of $4000 \mathrm{~cm}^{-1}$ to $600 \mathrm{~cm}^{-1}$. Three replicate measurements were recorded for each condition (Chen et al. 2017b). 


\section{Wide-angle X-ray diffraction (WXRD)}

A D/MAX 2200 X-ray diffractometer (Rigaku Corporation, Tokyo, Japan) was used to measure the WXRD patterns of the samples before and after modification. Prior to the measurement, the samples were placed onto the supporter and pressed compactly. Over the angular range of $2 \theta=5^{\circ}$ to $40^{\circ}$ and a step size of $5^{\circ} / \mathrm{min}$, the WXRD data was generated by a diffractometer with $\mathrm{Cu} \mathrm{K} \alpha$ radiation $(\lambda=1.542 \AA)$ at $40 \mathrm{kV}$ and $30 \mathrm{~mA}$. The degree of crystallinity, or crystallinity index (CI \%), was evaluated for each sample using Eq. 3 (Xuan et al. 2017),

$$
C I(\%)=\left(A_{c} / A_{a}\right) \times 100
$$

where $A_{\mathrm{c}}$ is the area of the crystalline reflection (\%) and $A_{\mathrm{a}}$ is the area (\%) subtending the whole diffraction profile. The WXRD jade software (MDI JADE 6.5, Materials Data, Inc., Livermore, CA, USA) was adopted to calculate the diffraction peaks (002), the crystalline reflection, and the area subtending the whole diffraction profile.

\section{Scanning electron microscopy (SEM)}

A QuanTa-200 environmental scanning electron microscope (QuanTa-200; FEI Company, Eindhoven, Netherlands) was used to observe the morphologies of the particleboard. The magnification was 500x. The samples were taken from the side cutting section. The samples were spray-coated with gold prior to the observation to enhance the surface conductivity and observed under SEM at an acceleration voltage of $15 \mathrm{Kv}$ ( $\mathrm{Li}$ et al. 2019).

\section{RESULTS AND DISCUSSION}

\section{Effects of Synthesis Conditions on the Mechanical Performance}

To investigate the effects of different process conditions (prepared by various NA/particles mass proportions) on the mechanical properties, the treated particles were utilized to manufacture homogeneous particleboard $(700 \mathrm{~mm} \times 700 \mathrm{~mm} \times 17 \mathrm{~mm})$ at different hot-pressing temperatures for $22 \mathrm{~min}$ (BY60222/2; Zhengtai Machinery Manufacturing Co., Ltd., Linyi, China). Figure 2 shows the hot-pressing curve of formaldehyde-free particleboards. The particleboard with UF resin adhesive (UF PT) was used as a comparison sample with the different hot-pressing temperatures.

Figures 3 and 4 show the results of the MOR and surface bonding strength of the particleboard by NA-Tannin and UF adhesive, which were processed with different NA/particle mass proportions, tannin concentrations, and hot-press temperatures. The MOR and surface bond strength of the formaldehyde-free particleboard showed an increasing trend with increases in the NA/particles mass proportion and tannin solution concentration. The maximum MOR was achieved by a mass proportion of 20:80 NA/particle mass proportion (15.1 MPa), which satisfied the satisfied the China National Standard GB/T 4897 (2015) (11.5 MPa). Compared with the UF resin adhesive particleboard, the MOR and surface bond strength of the particleboards treated with 20:80 NA/particle mass proportion increased $28.8 \%$ and $57.7 \%$, respectively, which signified that the bonding strength between the tannin and wood surface was promoted. With the increase of the concentration of tannin, the increase of surface bond strength was not significant, indicating that the contact between the particles was optimized to maximize the surface bond strength. However, when the temperature increased, the mechanical strength 
increased first and later decreased, which suggested that the steam in the cell cavity quickly escaped under a higher temperature. This resulted in greater pressure that broke the cell wall and caused the rupture of wood fiber, thereby reducing the fiber tensile strength.

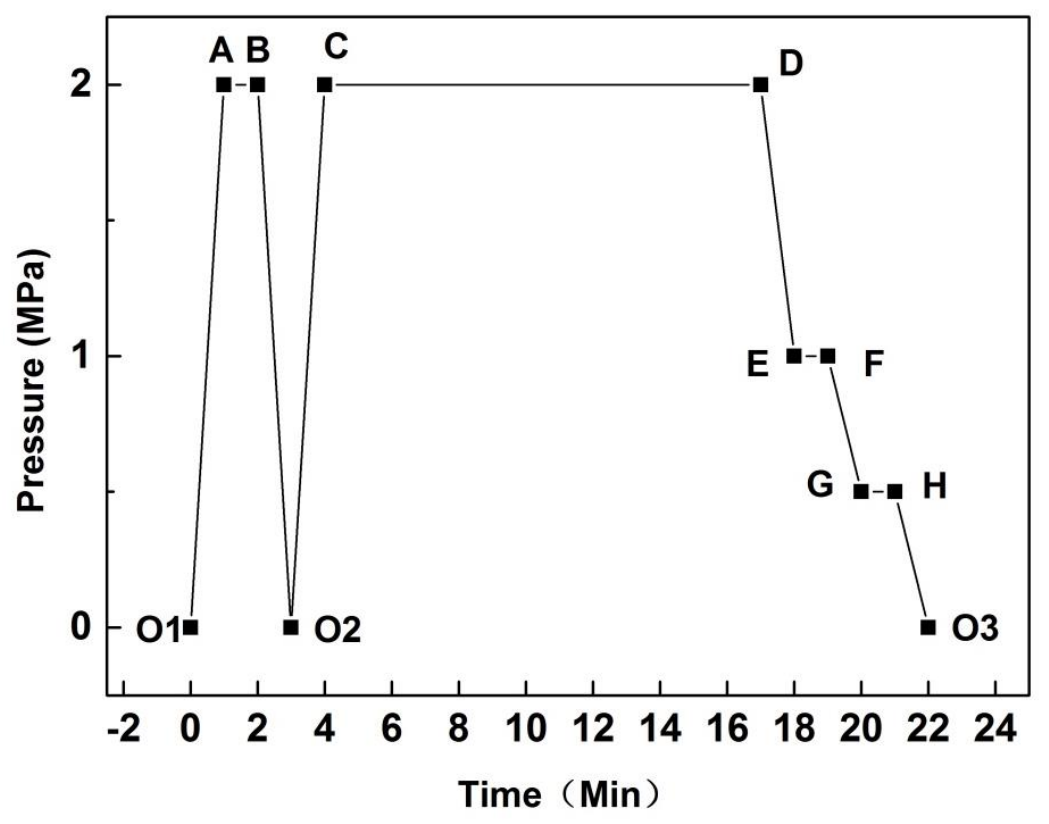

Fig. 2. Hot-pressing curve of formaldehyde-free particleboards

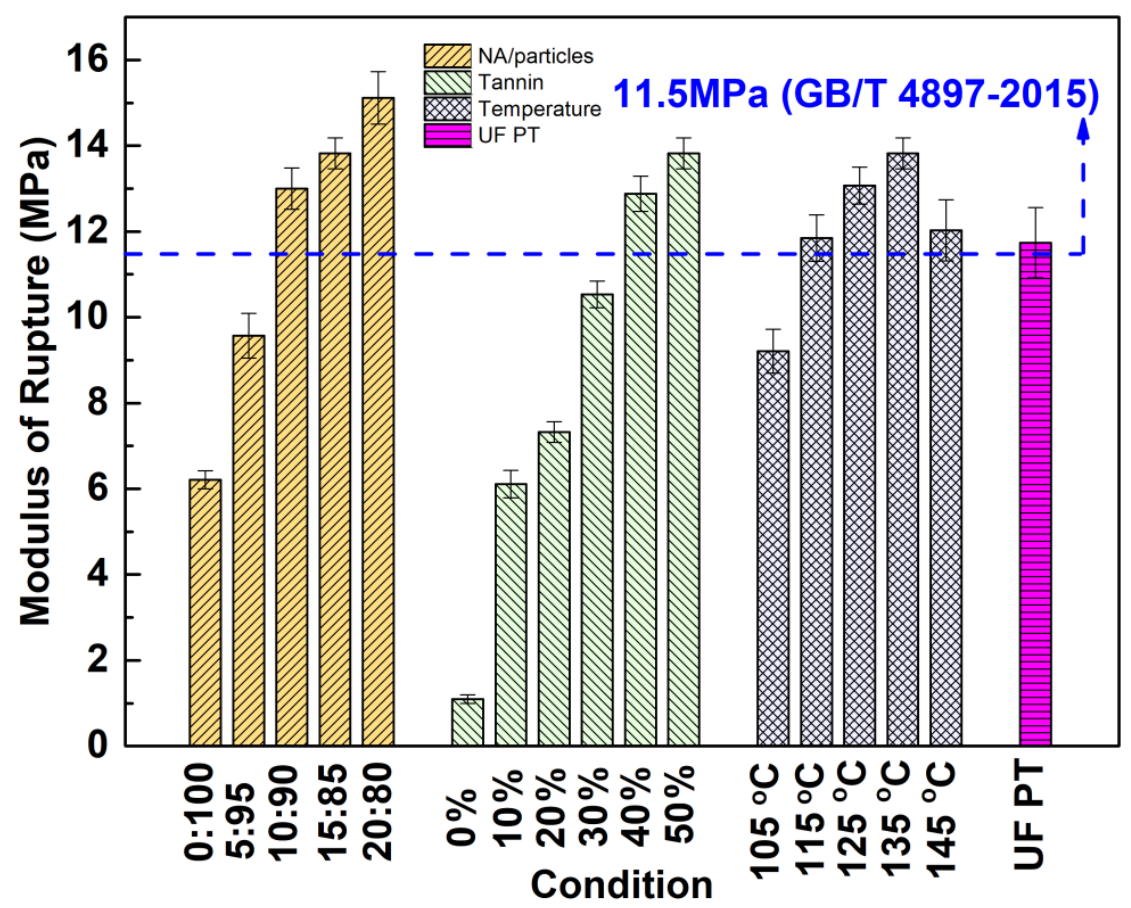

Fig. 3. Effects of the process conditions on modulus of rupture of formaldehyde-free particleboards 


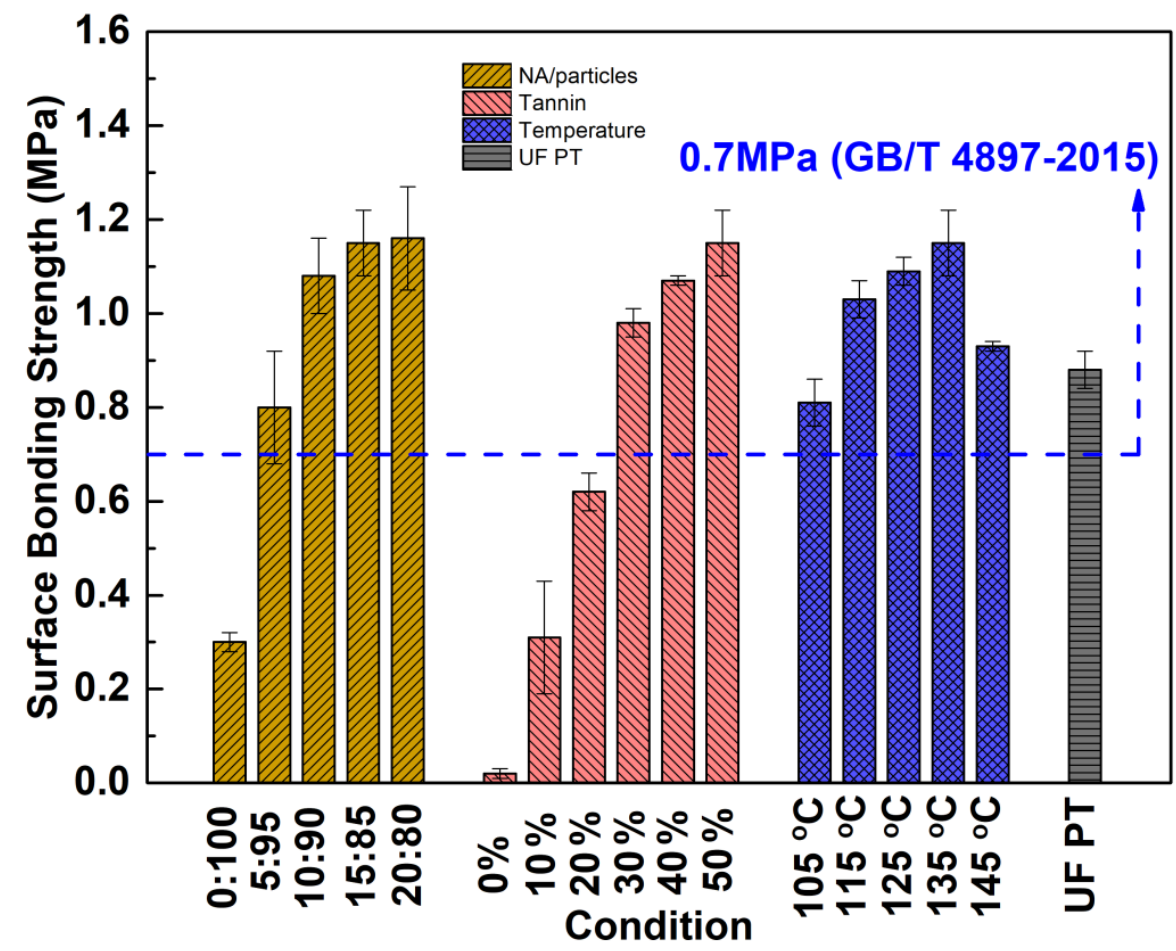

Fig. 4. Effects of the process conditions on surface bonding strength of formaldehyde-free particleboards

Figure 5 reveals the results of the internal bonding strength (IB) of the particleboard, which shows the same trend as the MOR. The higher temperature led to excessive vapor pressure and the increase of internal stress of the particleboard, which reduced the internal bond strength.

Figure 6 presents the process conditions during $2 \mathrm{~h}$ of thickness swelling of the formaldehyde-free particleboard. With the increase of the NA/particleboard mass proportion, tannin concentration, and temperature, the thickness swelling ratio of water absorption thickness decreased, which caused better dimensional stability for the particleboard in humid environments.

When low amounts of nitric acid and tannin were used, the bond between the particleboard was not tight, which increased the spring back of the slab after water absorption, resulting in the final increase of water absorption thickness expansion rate of the particleboard. This was consistent with the previous research (Zhao et al. 2020). In addition, compared with the UF resin adhesive particleboard, the MOR, surface bond strength, and IB of the particleboards treated by 20:80 NA/particle mass proportion increased $16.4 \%, 23.9 \%$, and $32.0 \%$, respectively. However, the mechanical strength of the particleboards with NA alone or tannin alone were much lower than when NA-tannin was added. 


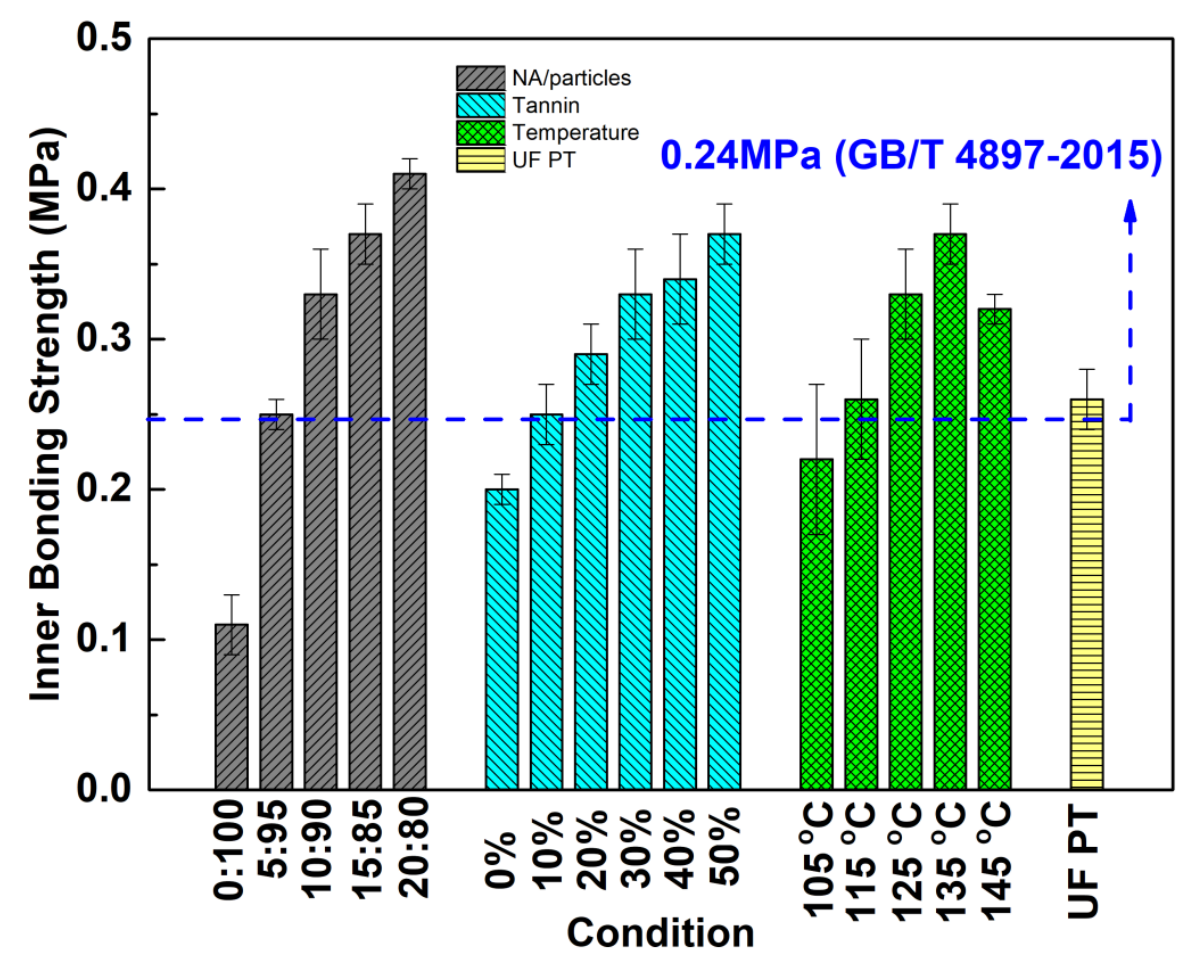

Fig. 5. Effects of the process conditions on inner bonding strength of formaldehyde-free particleboards

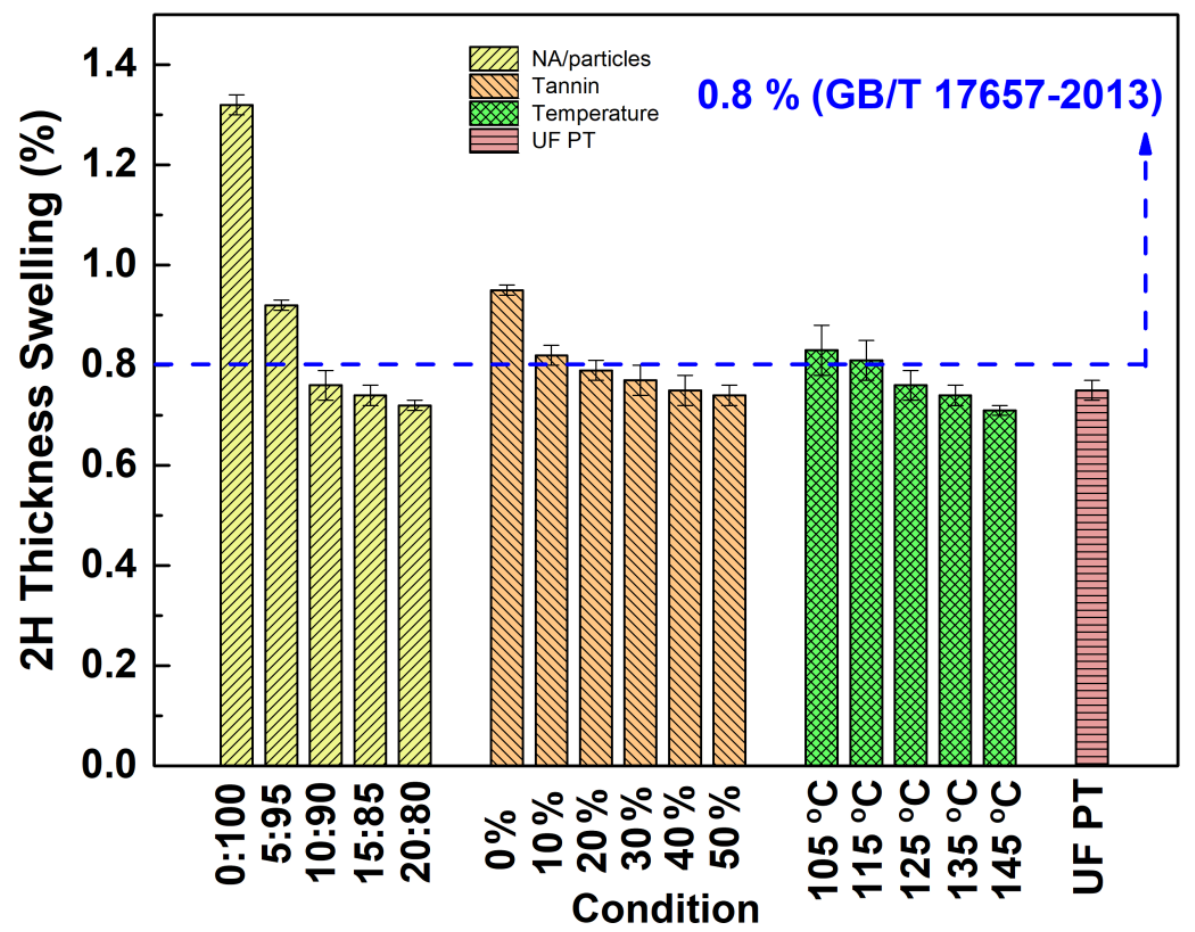

Fig. 6. Effects of the process conditions on $2 \mathrm{~h}$ thickness swelling of formaldehyde-free particleboards 


\section{FTIR Analysis}

The chemical changes of the particles before and after activation were measured by FTIR, and the results within the 600 to $4000 \mathrm{~cm}^{-1}$ region are shown in Fig. 7. Compared with non-activated particles, one new peak was generated from the activated particles. The new peak was located at $1650 \mathrm{~cm}^{-1}$ and could be attributed to nitro group vibration.

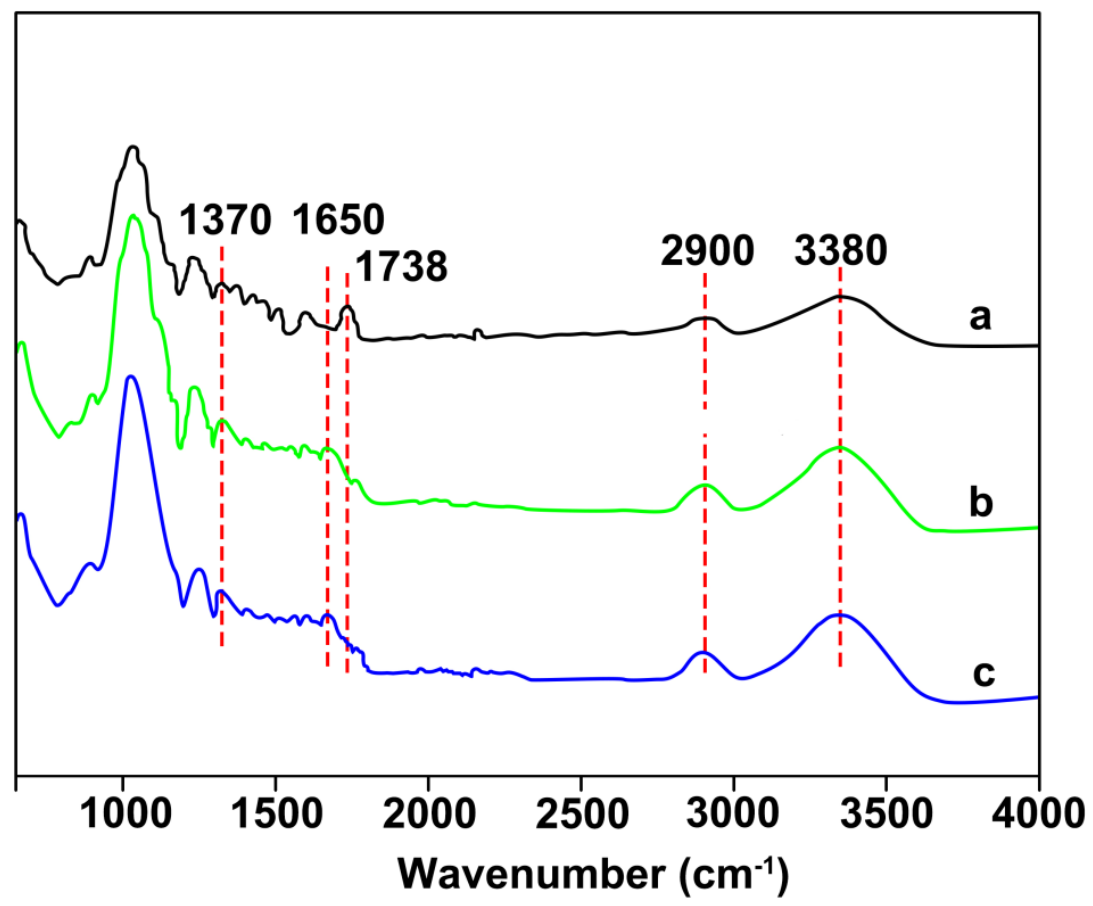

Fig. 7. Comparison of FTIR spectra obtained from particles: (a) untreated particles; (b) particles activated with 15/85 NA/particles mass proportion; (c) particles activated with 20/80 NA/particles mass proportion

According to previous studies, cellulose can be esterified with inorganic acid to replace hydroxyl groups on cellulose to form nitrate ester under dilute acid conditions (Short and Munro 1990). However, due to the low concentration of acid, the degree of substitution is limited. This new characteristic peak was consistent with the results of the former report.

Considering the composition of the wood cell and the involved chemical changes, the formation of a novel nitro group was possibly due to the nitration reaction between nitric acid and cellulose. In addition, the bending vibration of $\mathrm{C}-\mathrm{H}$ was reduced at 1370 $\mathrm{cm}^{-1}$, indicating that the absorption intensity was slightly weakened. This was the characteristic absorption peak of cellulose and hemicellulose, which indicated that nitric acid affected the cellulose and hemicellulose. The peak of $1738 \mathrm{~cm}^{-1}$ was the $\mathrm{C}=\mathrm{O}$ (acetyl group) stretching vibration of the hemicellulose, which showed that the peak was noticeably weakened after nitric acid activation treatment, indicating that the acetyl side chain of hemicellulose was decomposed. The peak shape of the $\mathrm{O}-\mathrm{H}$ stretching vibration at $3380 \mathrm{~cm}^{-1}$ narrowed, indicating that the binding force of the intermolecular hydrogen bond of cellulose decreased, and the swing range of the $\mathrm{O}-\mathrm{H}$ group in cellulose increased. The stretching vibration of C-H was $2900 \mathrm{~cm}^{-1}$, and the peak strength was weakened after treatment, which implied the methyl in hemicellulose and lignin were destroyed. 
Due to the poor stability of lignin, the ether bond was more likely to break and generate halogenated hydrocarbons and alcohols under acidic conditions. Therefore, the activation mechanism of nitric acid for particles should be described via three aspects: one is the diluted acid condition that destroyed the macromolecular chain structure of lignin and cellulose, in which, the phenolic hydroxyl groups and nitryl formed and the methoxy group on benzene ring was destroyed; the second is the destruction of the hydrogen bond on the surface of cellulose; and the third is the hydrolysate of hemicellulose under acid conditions during activation (Yang et al. 2007).

\section{Effect of the Nitric Acid Activation on the pH, Holocellulose Content, Pentosans, and Free Furfural of Particles}

Table 2 shows the $\mathrm{pH}$, holocellulose content, pentosans, and free furfural of the particles. The holocellulose content of the particles decreased with increasing nitric acid/particles mass proportion, because the nitric acid could promote the hydrolysis of cellulose molecules to produce short chain structures. The increasing acid condition hydrolyzed the cellulose unit into low-molecular-weight monosaccharides or furfural, thus reducing the holocellulose content.

After nitric acid activation, the $\mathrm{pH}$ of the particles had been decreased remarkably. The $\mathrm{pH}$ of the treated fibers under 15/85 NA/particles mass proportion was reduced to 3.7 from 5.3 for the untreated sample. Moreover, the $\mathrm{pH}$ of the particles decreased with increasing NA/particles mass proportion. During the treatment, the hemicellulose with its comparatively poor heat resistance partially degraded, losing its acetyl group. This was because the pentose obtained from hemicellulose easily produced furfural by pyrolysis under high temperature and acid conditions (Koti et al. 2016). A stronger acidity resulted in more pentose obtained from the decomposition of hemicellulose. Free furfural was detected in hot-pressed particles, which indicated that furfural was formed during the hotpressing process and polycondensation of tannins. This was due to furfural being used as the curing agent and was one considered synthesis mechanism. The polycondensation of furfural and tannin was also credited with increased water resistance and inner bonding strength.

Table 2. The $\mathrm{pH}$, Holocellulose Content, Pentosans, and Free Furfural of Particles

\begin{tabular}{|c|c|c|c|c|}
\hline Binding Method & $\mathrm{pH}$ & $\begin{array}{c}\text { Holocellulose Content } \\
(\%)\end{array}$ & $\begin{array}{c}\text { Pentosans } \\
(\%)\end{array}$ & Free Furfural (\%) \\
\hline NA/particles (5/95) & 4.6 & 69.2 & 21.1 & 0.36 \\
\hline NA/particles (10/90) & 4.1 & 66.3 & 25.4 & 0.37 \\
\hline NA/particles (15/85) & 3.7 & 62.1 & 29.7 & 0.43 \\
\hline $\begin{array}{c}\text { NA/particles (15/85)-tannin } \\
(30 \%)\end{array}$ & 3.5 & 58.2 & 16.2 & 1.47 \\
\hline $\begin{array}{c}\text { NA/particles (15/85)-tannin } \\
(40 \%)\end{array}$ & 3.1 & 57.4 & 14.5 & 0.98 \\
\hline $\begin{array}{c}\text { NA/particles (15/85)-tannin } \\
(50 \%)\end{array}$ & 2.9 & 49.5 & 11.2 & 0.95 \\
\hline $\begin{array}{c}\text { Un-treated particles } \\
\text { Notes }\end{array}$ & 5.3 & 76.1 & 20.6 & 0.33 \\
\hline
\end{tabular}




\section{WXRD Analysis}

Figure 8 illustrates the WXRD patterns obtained for the un-activated and activated particles. As shown in Fig. 2, the (002) diffraction peaks recorded for the un-activated and activated particles were both centered at approximately $22.5^{\circ}$ (ranging from $21.32^{\circ}$ to $22.88^{\circ}$ ). This result indicated that the activated process resulted in a limited change of the crystalline regions of particles and a minimal effect on the distance between crystal layers. A new small diffraction peak was generated at $28.5^{\circ}$, which demonstrated that there was a small amount of crystal formation or crystal reorientation in the activation process.

When the mass proportion (NA/particles) was 5/95 and 10/90, the relative crystallinity of cellulose decreased $1.4 \%$ and $2.2 \%$. Meanwhile, with the mass proportion (NA/particles) of $15 / 85$, the cellulose crystallinity decreased to $46.1 \%$, which was $6.2 \%$ lower than that of the untreated sample. That is because the cellulose macromolecular chain was composed of a crystalline region and an amorphous region. Nitric acid and water entered the amorphous region of cellulose, in which hydrolysis reduced the degree of polymerization of long cellulose chains. In addition, the hydrogen bonds in the crystalline region of cellulose were released, exposing more hydroxyl groups in the crystalline region.

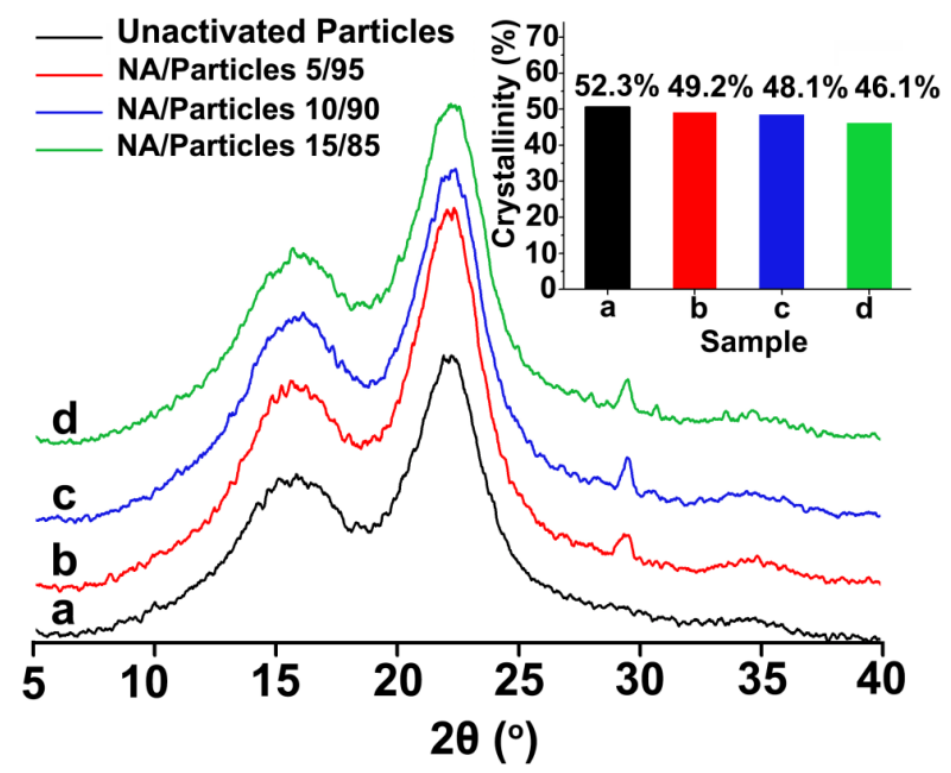

Fig. 8. WXRD patterns obtained for particles by nitric activation: (a) Untreated particles; (b) 5/95 NA/particles mass proportion; (c) 10/90 NA/particles mass proportion; (d) 15/85 $\mathrm{NA} /$ particles mass proportion

\section{SEM Analysis}

Figure 9 shows the surface morphology of the composite samples after nitric acidtannin treatment (magnification 500x). The urea formaldehyde resin particleboard and formaldehyde-free particleboard were compared using an electron microscope. Compared with the side section of particleboard, the resin of urea formaldehyde resin adhesive can be seen clearly in the figure. However, the joint between particles treated with NA-tannin was tight. There were no obvious traces of resin between the particles. 


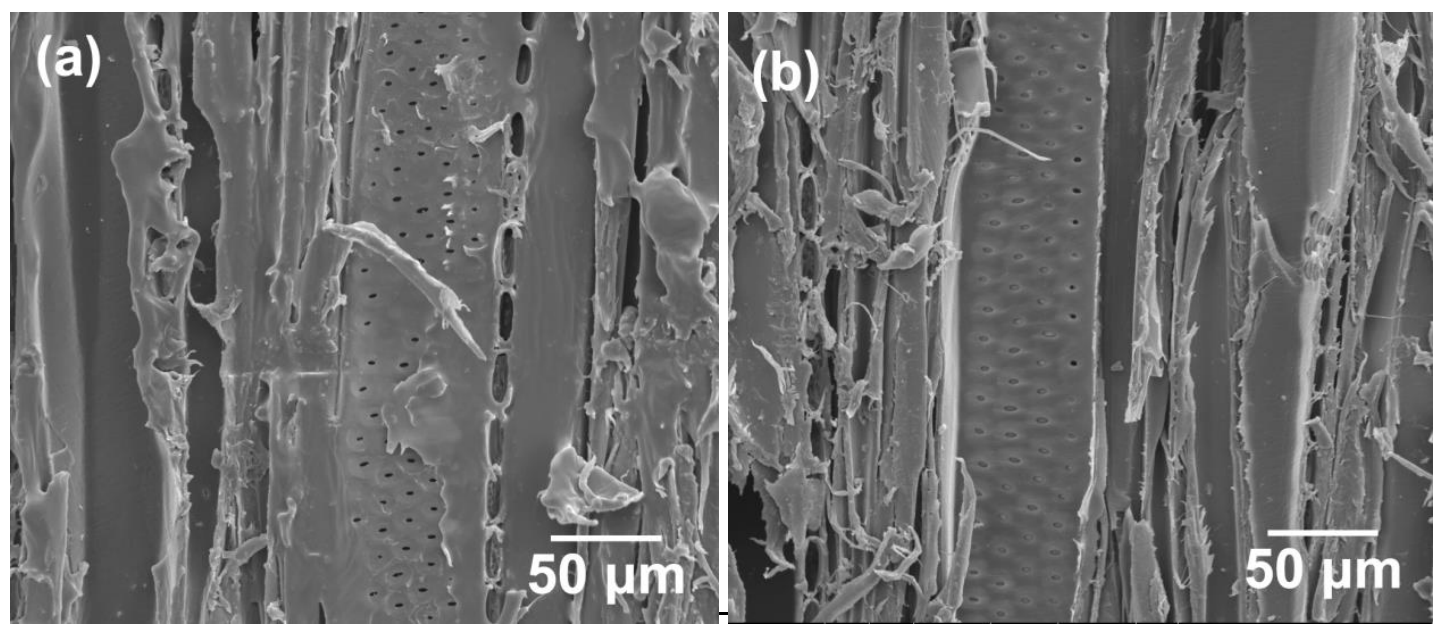

Fig. 9. Surface morphology of the particleboard (magnification 500x) under: (a) UF resin adhesive particleboard; (b) nitric acid-tannin treatment (15/85 NA/particles mass proportion, $50 \%$ tannin concentration, and $135^{\circ} \mathrm{C}$ hot-press temperature)

According to the FTIR results, chemical component changes, WXRD, and SEM, a scheme of the chemical reaction of particleboard treated with nitric acid-tannin treatment was created and is shown in Fig. 10. Pentose was formed using hemicellulose acid and decomposed into furfural by heat treatment. Under the catalysis of acid, the hydroxyl group on the tannin was replaced by the aldehyde group on furfural to form alkane, which led to a polycondensation reaction. In addition, the hydroxyl group on the tannin was close to the hydroxyl group of cellulose molecules on the fiber to form hydrogen bonds, which made the particles closely bonded. The binding water inside the particles escaped under the hot condition, and the hydroxyl groups between the cellulose molecules were connected by hydrogen bonds again, which further improved the bonding properties of the particleboard. The above reaction determines the good mechanical properties of formaldehyde free particleboard.

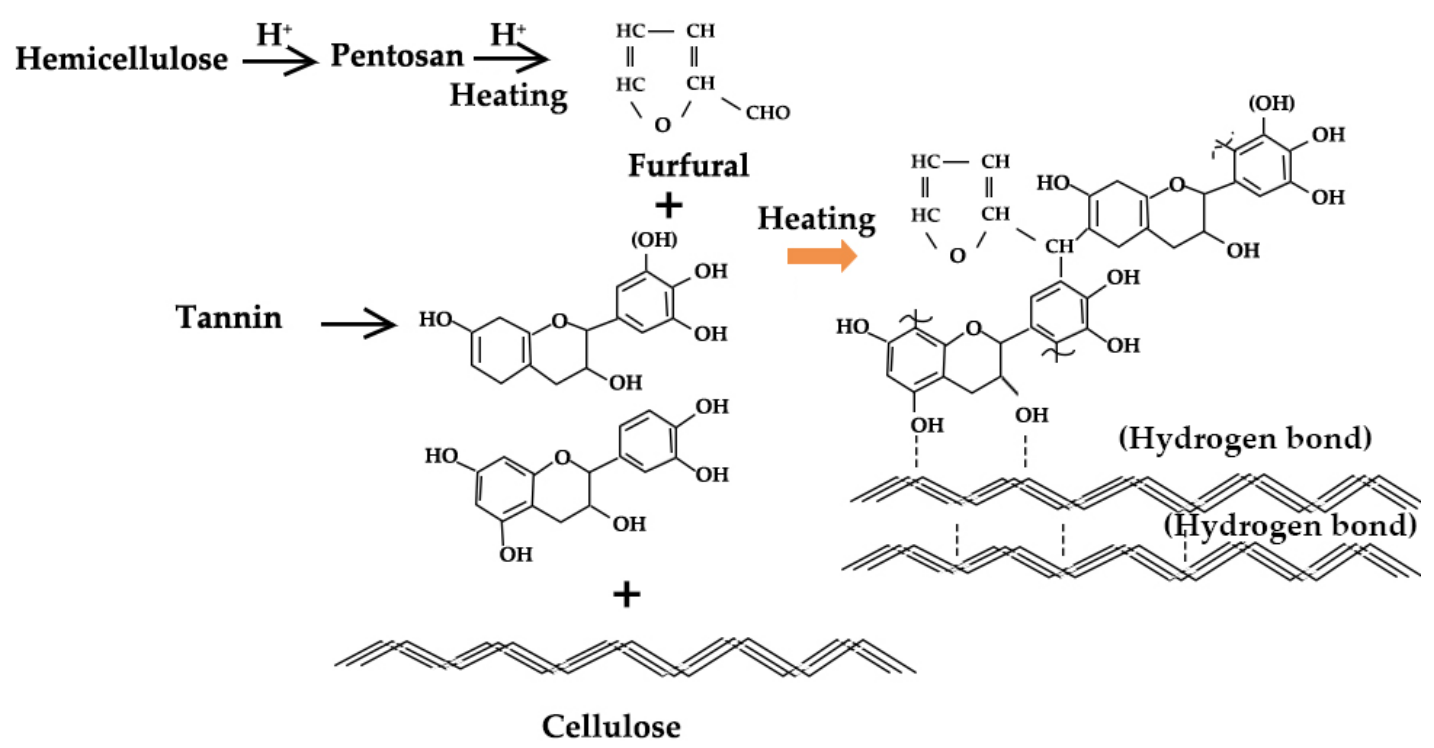

Fig. 10. Possible reaction process of particles, nitric acid, and tannin 
The curing behavior and optimal hot-pressing conditions (such as reducing energy consumption of hot pressing by controlling hot pressing time and temperature and increased bond performance) will be investigated in further research by the authors.

\section{CONCLUSIONS}

1. A novel formaldehyde-free particleboard method was investigated using nitric acid and tannin under hot-pressing conditions. The effects of different synthesis conditions (such as nitric acid mass proportion, tannin mass proportion, and hot-pressing temperature) on the bonding performance of particleboard were investigated. The results for the surface bonding strength, MOR, inner bonding strength, and $2 \mathrm{~h}$ TS tests achieved the China National Standard requirements. When the particleboard was bonded with the mass proportion of 20/80 NA/particles, $50 \%$ tannin concentration, and $135^{\circ} \mathrm{C}$ temperature, the MOR, surface bonding strength, inner bonding strength, and 2 $\mathrm{h}$ TS were better than that of the control sample.

2. The results of FTIR showed that nitric acid activation of the particles decomposed hemicellulose into pentose, thus exposing more cellulose on the surface of the particles. Cellulose hydrolyzed under the action of acid, which exposed more hydroxyl groups in the crystallized and amorphous areas, and then increased the number of hydrogen bond junctions between the particles in the hot-pressing process. The WXRD of the wood particles showed that the activation treatment destroyed the hydrogen bond structure of cellulose and produced new crystalline variants, which enhanced the activity of hydroxyl groups on the surface of the wood particles.

3. Chemical analysis showed that free furfural was detected in the particleboard after hot pressing, which indicated that furfural was decomposed from pentose during hot pressing. The tannin resin, possibly formed by the cross-linking reaction of furfural and tannin after acid treatment and heat treatment, improved the bonding performance of the board. In addition, the binding water inside the particles escaped under the hot conditions, and the hydroxyl groups between the cellulose molecules were connected by hydrogen bonds again, which further improved the bonding properties of the particleboard. From the SEM analysis, the bonding between particles was close, and a small amount of resin appeared on the surface of the particles.

4. The preliminary results of this study showed that nitric acid and tannin could be utilized as a method for formaldehyde-free particleboard.

\section{ACKNOWLEDGMENTS}

This work was financially supported by the National Natural Science Foundation of China (Grant No. 31901243). Feng Chen and Baichuan Wang conceived of, designed, and performed the experiments. Xinghua Xia and Feng Chen analyzed and discussed the data. Feng Chen wrote the manuscript, with revisions by Xinghua Xia. 


\section{REFERENCES CITED}

Chen, F., Han, G., Li, Q., Gao, X., and Cheng, W. (2017a). "High-temperature hot air/silane coupling modification of wood fiber and its effect on properties of wood fiber/HDPE composites," Materials 10(3), Article number 286. DOI: 10.3390/ma10030286

Chen, F., Li, Q., Gao, X., Han, G., and Cheng, W. (2017b). "Impulse-cyclone drying treatment of poplar wood fibers and its effect on composite material's properties," BioResources 12(2), 3948-3964. DOI: 10.15376/biores.12.2.3948-3964

Gao, X., Li, Q., Cheng, W., Han, G., and Xuan, L. (2017). "High temperature and pressurized steaming/silane coupling co-modification for wood fibers and its effect on the properties of wood fiber/HDPE composites," Macromolecular Research 25(2), 141-150. DOI: 10.1007/s13233-017-5024-X

GB/T 2677.9 (1994). "Fibrous raw material--Determination of pentosan," Standardization Administration of China, Beijing, China.

GB/T 2677.10 (1995). "Fibrous raw material--Determination of holocellulose," Standardization Administration of China, Beijing, China.

GB/T 4897 (2015). "Particleboard," Standardization Administration of China, Beijing, China.

GB/T 6043 (2009). "Method for determination of PH value of wood," Standardization Administration of China, Beijing, China.

GB/T 11718 (2009). "Medium density fibreboard," Standardization Administration of China, Beijing, China.

GB/T 17657 (2013). "Test methods of evaluating the properties of wood-based panels and surface decorated wood-based panels," Standardization Administration of China, Beijing, China.

Hameed, Y., Idris, A., Hussain, S. A., and Abdullah, N. (2016). “A tannin-based agent for coagulation and flocculation of municipal wastewater: Chemical composition, performance assessment compared to polyaluminum chloride, and application in a pilot plant," Journal of Environmental Management 184(Part 3), 494-503. DOI: 10.1016/j.jenvman.2016.10.033

Han, J., Yue, Y., Wu, Q., Huang, C., Pan, H., Zhan, X., Mei, C., and Xu, X. (2017). "Effects of nanocellulose on the structure and properties of poly (vinyl alcohol)-borax hybrid foams," Cellulose 24(10), 4433-4448. DOI: 10.1007/s10570-017-1409-4

Koti, S., Govumoni, S. P., Gentela, J., and Rao, L. V. (2016). "Enhanced bioethanol production from wheat straw hemicellulose by mutant strains of pentose fermenting organisms Pichia stipitis and Candida shehata," SpringerPlus 5(1). DOI10.1186/s40064-016-3222-1

Li, C., Zhang, J., Yi, Z., Yang, H., Zhao, B., Zhang, W., and Li, J. (2016). "Preparation and characterization of a novel environmentally friendly phenol-formaldehyde adhesive modified with tannin and urea," International Journal of Adhesion and Adhesives 66, 26-32. DOI: 10.1016/j.ijadhadh.2015.12.004

Li, Y., Yang, G., and Chen, J. (2013). "Optimization of the-hydrolysis parameters of dissolving pulp of fast-growing poplar producing," Advanced Materials Research 690-693, 1354-1357. DOI: 10.4028/www.scientific.net/AMR.690-693.1354

Li, W., Chen, L., and Li, X. (2019). "Comparison of physical-mechanical and mouldproof properties of furfurylated and DMDHEU-modified wood," BioResources 14(4), 9628-9644. DOI: 10.15376/biores.14.4.9628-9644 
Ma, P., Chen, B., and Di, M. (2018). "Activation processes of wood fiber under freezing by $\mathrm{NaOH}$ /urea aqueous solution," Biomass Chemical Engineering 52(3), 16-22. DOI: 10.3969/j.issn.1673-5854.2018.03.003

Piscitelli, A., Amore, A., and Faraco, V. (2012). "Last advances in synthesis of added value compounds and materials by laccase mediated biocatalysis," Current Organic Chemistry 16(21), 2508-2524. DOI: 10.2174/138527212804004571

Pizzi, A. (2006). "Recent developments in eco-efficient bio-based adhesives for wood bonding: Opportunities and issues," Journal of Adhesion Science and Technology 20(8), 829-846. DOI: 10.1163/156856106777638635

Short, R. D., and Munro, H. S. (1990). "Aspects of the surface and bulk nitration of cellulose in nitric acid, nitric acid/water, and nitric acid/dichloromethane mixes," Journal of Applied Polymer Science 39(9), 1973-1982. DOI: 10.1002/app.1990.070390913

Song, W., Zhang, K., Chen, Z., Hong, G., Lin, J., Hao, C., and Zhang, S. (2018). "Effect of xylanase-laccase synergistic pretreatment on physical-mechanical properties of environment-friendly self-bonded bamboo particleboards," Journal of Polymers and the Environment 26, 4019-4033. DOI: 10.1002/app.23538

Sun, S., and Zhao, Z. (2018). "Influence of acid on the curing process of tannin-sucrose adhesives," BioResources 13(4), 7683-7697. DOI: 10.15376/biores.13.4.7683-7697

Sun, S., Zhang, M., Umemura, K., and Zhao, Z. (2019). "Investigation and characterization of synthesis conditions on sucrose-ammonium dihydrogen phosphate (SADP) adhesive: Bond performance and chemical transformation," Materials (Basel) 12(24), Article number 4078. DOI: 10.3390/ma12244078

Wang, Y. B., Song, K., and Zhang, S. B. (2010). "The research progress in pretreatment techniques of self-bonding composites," Advanced Materials Research 113-116, 2337-2343. DOI: 10.4028/www.scientific.net/AMR.113-116.2337

Xuan, L., Han, G., Wang, D., Cheng, W., Gao, X., Chen, F., and Li, Q. (2017). "Effect of surface-modified $\mathrm{TiO}_{2}$ nanoparticles on the anti-ultraviolet aging performance of foamed wheat straw fiber/polypropylene composites," Materials (Basel) 10(5), Article number 456. DOI: 10.3390/ma10050456

Yang, H., Yan, R., Chen, H., Lee, D. H., and Zheng, C. (2007). "Characteristics of hemicellulose, cellulose and lignin pyrolysis," Fuel 86(12), 1781-1788. DOI: 10.1016/j.fuel.2006.12.013

Zhang, D., Zhang, A., and Xue, L. (2015). "A review of preparation of binderless fiberboards and its self-bonding mechanism," Wood Science and Technology 49, 661-679. DOI: 10.1007/s00226-015-0728-6

Zhao, Z., Miao, Y., Yang, Z., Wang, H., Sang, R., Fu, Y., Huang, C., Wu, Z., Zhang, M., Sun, S., et al. (2018). "Effects of sulfuric acid on the curing behavior and bonding performance of tannin-sucrose adhesive," Polymers 10, 1-13. DOI:

10.3390/polym 10060651

Zhao, Z., Sakai, S., Wu, D., Chen, Z., Zhu, N., Huang, C., Sun, S., Zhang, M., Umemura, K., and Yong, Q. (2019). "Further exploration of sucrose-citric acid adhesive: Investigation of optimal hot-pressing conditions for plywood and curing behavior," Polymers 11(12), Article number 1996. DOI: 10.3390/polym11121996

Zhao, Z., Huang, C., Wu, D., Chen, Z., Zhu, N., Gui, C., Zhang, M., Umemura, K., and Yong, Q. (2020). "Utilization of enzymatic hydrolysate from corn stover as a precursor to synthesize an eco-friendly plywood adhesive," Industrial Crops \& Products 152. DOI:10.1016/j.indcrop.2020.112501 
Zheng, N., Wu, D., Sun, P., Liu, H., Luo, B., Li, L. (2019). "Mechanical properties and fire resistance of magnesium-cemented poplar particleboard," Materials 12(19), Article number 3161. DOI: 10.3390/ma12193161

Article submitted: April 24, 2020; Peer review completed: June 13, 2020; Revised version received and accepted: June 21, 2020; Published: June 24, 2020.

DOI: 10.15376/biores. 15.3.6165-6180 